\title{
Photochemical Generation of Superbases and Its Application to Photoreactive Materials
}

\author{
Koji Arimitsu* and Ryosuke Endo \\ Department of Pure and Applied Chemistry, Faculty of Science and Technology, \\ Tokyo University of Science, 2641 Yamazaki, Noda, Chiba 278-8510, Japan \\ arimitsu@rs.noda.tus.ac.jp
}

Keywords: photobase generator, photodecarboxylation, ketoprofen, superbase

Only a few articles have mentioned photoreactive materials relying on base-catalyzed reactions although a large number of investigations concerning analogous systems utilizing acid-catalyzed reactions such as chemically amplified photoresists[1] and cationic UV-curing materials[2] have been reported. This is probably due to relatively low quantum yields for photobase generation and weaker basicity of photogenerated bases, leading to low photosensitivity of photoreactive materials doped with photobase generators. Furthermore, many of the photobase -generators reported are generally prepared via several synthetic steps.[3-5] On the other hand, it is well known that ketoprofen (1) undergoes photodecarboxylation reaction with high quantum yield ( $\Phi=0.75$ ) upon UV-irradiation (Scheme 1).[6] We have reported that a salt consisting of $\mathbf{1}$ and an aliphatic amine can act as a highly effective photobase generator.[7,8] If we use a superbase instead of an aliphatic amine, a free superbase should be photochemically produced with high efficiency. This idea led us to carry out the molecular design of novel photobase generators, $\mathbf{2 a}$ and $\mathbf{2 b}$, which can be simply prepared by mixing 1 with corresponding superbases, DBU and $\mathrm{DBN}$, respectively. Our primary concern in this paper is to demonstrate photochemical generation of superbases from the salts and to show that a novel photopolymer system is realized by the combination of the salt with an epoxy polymer (PGMA).

A solution of 1 and DBU or DBN in diethyl ether was stirred at room temperature for $1 \mathrm{hr}$. The solution was evaporated to afford $\mathbf{2} \mathbf{a}$ and $\mathbf{2} \mathbf{b}$ in good yields. Photodecomposition of $\mathbf{2 a}$ and $\mathbf{2} \mathbf{b}$ was investigated in methanol by UV-Vis absorption spectral measurements. Fig. 1 shows UV spectral changes of $\mathbf{2 a}$ in methanol upon irradiation with $254 \mathrm{~nm}$-light. As shown in Fig. 1, the absorption band at longer wavelength side of $\lambda_{\max }$ at $255 \mathrm{~nm}$ decreased slightly, and new band appeared at $230 \mathrm{~nm}$. $\mathbf{2 b}$ decomposed in a same way. These suggest that photodecarboxylation reaction of $\mathbf{2} \mathbf{a}$ and $\mathbf{2} \mathbf{b}$ proceeded in methanol. Upon addition of irradiated methanol solution of<smiles>CCc1cccc(C(=O)c2ccccc2)c1</smiles>

Scheme 1 Preparation of photobase generators $(\mathbf{2 a}, \mathbf{2 b}$, and $\mathbf{2 c})$ and their application to photopolymers 
2a to the methanol solution of phenol red, a new band at $560 \mathrm{~nm}$ appeared, assigned to the deprotonated phenol red after reaction with released base, and its intensity increased with an increase of irradiation energy (Fig. 2). These results show that $\mathbf{2 a}$ and $\mathbf{2 b}$ underwent photodecarboxylation reactions in methanol upon UV-irradiation, giving rise to the formation of free superbases.

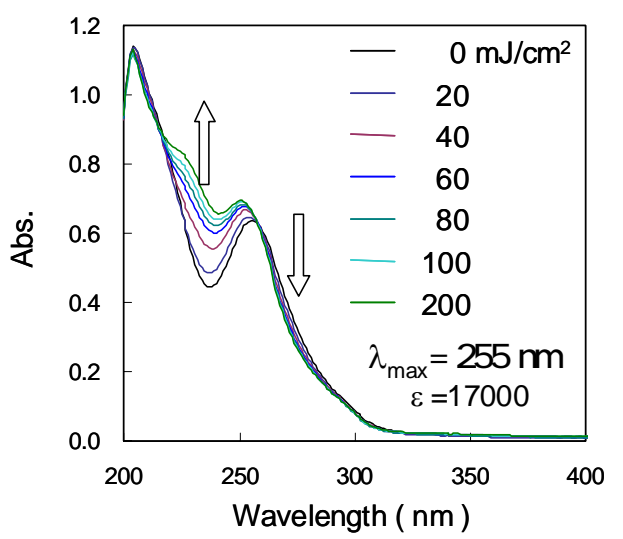

Fig. 1 UV spectral changes of 2 a $\left(3.0 \times 10^{-5}\right.$ $\mathrm{mol} / \mathrm{L}$ ) in methanol during $254 \mathrm{~nm}$-light irradiation.

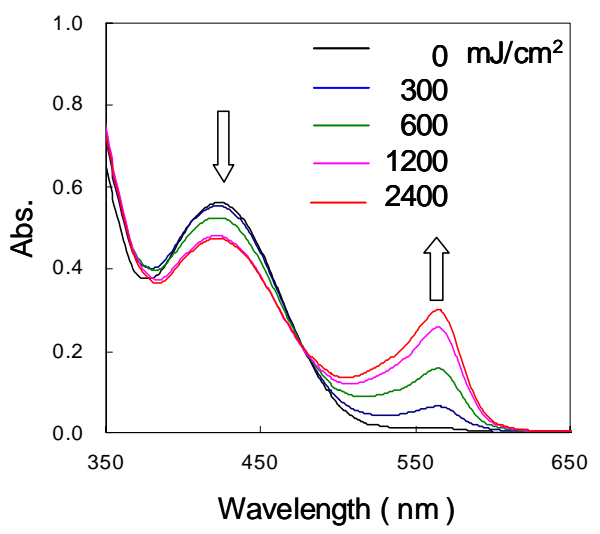

Fig. 2 Changes of UV-Vis spectra of phenol red solution upon addition of a solution of $\mathbf{2 a}$ being irradiated over time.

A photopolymer solution was prepared by dissolving $0.1 \mathrm{~g}$ of PGMA and $2 \mathrm{a}$ or $\mathbf{2 c}(2 \mathrm{~mol} \%$ relative to monomer units of PGMA) in chloroform. The solution was spin-coated on silicon wafers and baked at $80^{\circ} \mathrm{C}$ for $30 \mathrm{sec}$ to give thin films. The films were exposed to 254 nm-light, followed by heating at $80^{\circ} \mathrm{C}$ for $10 \mathrm{~min}$ to be subjected to the development with chloroform to give photosensitivity curves. As shown in Fig. 3, PGMA film doped with 2a functioned as a negative-working photoresist. This is because of that DBU generated from 2a caused cross-linking reactions of PGMA. On the other hand, PGMA film sensitized with 2c did not become insoluble. This means that basicity of cyclohexylamine generated from $\mathbf{2 c}$ is too weak to induce the cross-linking reactions of PGMA.

In summary, we developed novel and powerful photobase generators $\mathbf{2 a}$ and $\mathbf{2 b}$ to release superbases with high efficiency. These photobase generators were simply prepared by mixing ketoprofen (1) and a corresponding superbase. We also demonstrated that these photobase generators acted as an effective phototrigger for base-catalyzed cross-linking reactions of epoxy polymers.

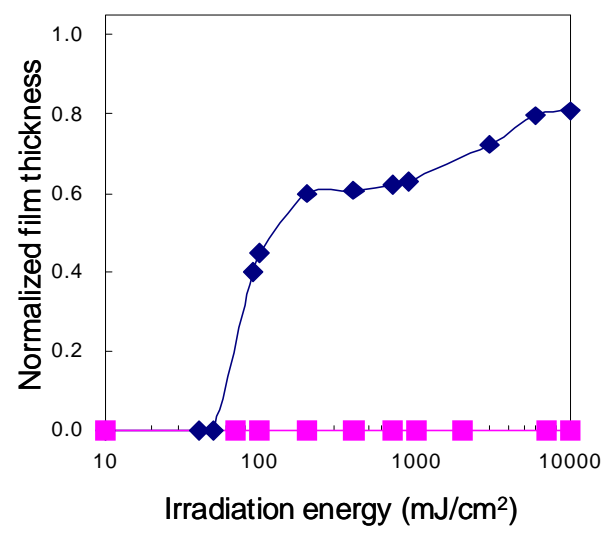

Fig. 3 Photosensitivity curves of PGMA films containing 2 mol\% of $\mathbf{2 a}(\boldsymbol{)})$ and $\mathbf{2 c}(\boldsymbol{\square})$.

\section{References}

1. H. Ito, Adv. Polym. Sci. 172 (2005) 37.

2. J. V. Crivello, J. Coatings Technol. 63 (1991) 35.

3. J. M. J. Fréchet, Pure Appl .Chem. 64 (1992) 1239.

4. M. Shirai, M. Tsunooka, Prog. Polym. Sci. 21 (1996) 1.

5. K. Suyama, M. Shirai, Prog. Polym. Sci. 34 (2009) 194.

6. L. L. Costanzo, G. De Guidi, G. Condorelli, A. Cambria, M. Fama Photochem. Photobiol. 50 (1989) 359.

7. K. Arimitsu, A. Kushima, H. Numoto, T. Gunji, Y. Abe, K. Ichimura, Polymer Preprints, Japan 54 (2005) 1357.

8. K. Arimitsu, A. Kushima, R. Endo, J. Photopolym. Sci. Technol. 22 (2009) 663. 